\title{
The relationship of multifocality and tumor burden with various tumor characteristics and survival in early breast cancer
}

\author{
G. KELEMEN ${ }^{1}$, V. FARKAS ${ }^{1}$, J. DEBRAH ${ }^{1}$, K. ORMANDI ${ }^{2,5}$, A. VOROS ${ }^{3}$, L. KAIZER ${ }^{3}$, Z. VARGA ${ }^{1}$, G. LAZAR ${ }^{4}$, Z. KAHAN ${ }^{1, *}$ \\ ${ }^{1}$ Department of Oncotherapy, ${ }^{2}$ Department of Radiology, ${ }^{3}$ Department of Pathology, ${ }^{4}$ Department of Surgery, University of Szeged, ${ }^{5}$ Euromedic \\ Diagnostics Hungary Ltd., Szeged, Hungary
}

${ }^{*}$ Correspondence: kahan.zsuzsanna@med.u-szeged.hu

Received November 29, 2011 / Accepted April 13, 2012

\begin{abstract}
The presence of multifocality and the aggregate tumor size were retrospectively analysed in a database of 1071 operated breast cancers. Around a quarter of all these cancers involved multiple foci, while a tenth of the total demonstrated more than one invasive focus. Although the multifocal cancers were smaller and more often screen-detected than the unifocal cancers, their aggregate tumor size was larger, and they more frequently displayed casting-type calcifications in the mammogram and HER2 positivity. Lobular histology favoured larger tumor burden. The invasive multifocal cancers were more commonly lymph node-positive than the other tumors. In a subgroup of 584 patients with a median follow-up time of 5 years, the larger size of the invasive tumor, the presence of LVI or lymph node involvement, HER2 positivity and triple negativity were associated with a poorer RFS and OS, while the outcome of screen-detected tumors was superior to that of non-screendetected or interval cancers. A large tumor size, lymph node positivity and HER2 positive or triple negative phenotypes were independent determinants of a poorer survival rate.
\end{abstract}

Key words: breast cancer, multifocality, prognostic factor, tumor burden

Breast carcinoma is a diverse disease entity, and the therapy should be based on specific markers reflecting its individual biological behaviour [1-3]. The tumor stage is one of the most relevant factors determining the outcome. The currently used prognostic factors, however, do not reliably distinguish between true early breast cancers (usually screen-detected and small, with a cure rate of around 95\%), and those that exhibit an apparently low TNM status, but in fact are at a more advanced stage with a high risk of relapse [3-6]. Since the panorama of breast cancers in the era of mammographic breast screening is even more heterogeneous than previously, intensive investigations have been devoted to the identification of new factors that might facilitate prognosis prediction, and could assist decision-making concerning adjuvant therapy. Features that have been considered include the mode of detection $[4,6,7]$, the mammographic appearance of the tumor [2, 8 ], and the subgross morphology of the tumor, including the distribution and the extent of the lesion $[9,13]$.

The prognostic significance of multifocality/multicentricity and the tumor burden have long been the subjects of investigation, but the results are inconclusive as the nomenclature and methods applied were not uniform [1, 12-17]. In general, multifocality is defined as the presence of two or more tumor foci separated by normal breast parenchyma. Some studies have attempted to take into consideration the entire tumor burden from the aspect of the outcome, by using the aggregate measure of the dimensions or volumes of the tumor foci [9, $10,14,16]$. A larger tumor burden due to multifocality has been related to poorer pathological characteristics $[1,12,14]$, relapse-free survival $[12,17]$ and survival $[12,15,16,18]$. In the case of multifocal breast cancers, therefore, a consideration of the TNM stage alone, would lead to inaccurate conclusions during treatment decision-making.

Our aims in the present study were to evaluate how the multifocality and calculated tumor burden in operable breast carcinomas relate to conventional pathological and other tumor features, and to assess their effects on the outcome.

\section{Patients and methods}

Study population. The patient- and tumor-related data on women attending the Breast Unit at the University of Szeged 
with invasive breast cancer in clinical stage I or II between May 2004 and August 2010 were prospectively collected. All these patients underwent primary breast surgery, and adjuvant therapy was administered in accordance with the national and international guidelines.

Prospective data collection. The data recorded were the age of the patient at the time of breast surgery, the mode of detection of the breast cancer (mammography screeningdetected, detected other than by mammography screening or interval cancer) and its mammographic appearance, classified as published earlier $[2,19]$. Briefly, the radiologic images were categorized as stellate (spiculated) tumor masses, circular tumors, and parenchymal dystorsion/asymmetric density, while malignant microcalcifications were categorized into two groups: casting-type calcifications and non-casting-type calcifications. For the analysis of the association between the mammographic image and survival, these categories were grouped as: stellate lesions without casting-type calcifications, casting-type calcifications with or without an associated tumor mass and others. The type of breast surgery (breast-conserving surgery vs. mastectomy), the type of lymph node surgery (sentinel lymph node biopsy vs. axillary lymph node dissection with or without sentinel lymph node biopsy), the pathological size of the largest invasive focus ( $\mathrm{pT}$ ), the histological type, the histological grade, the presence of lymphovascular invasion (LVI) and the information on lymph node involvement were also compiled. The percentages of cells expressing the oestrogen receptor (ER), the progesterone receptor (PR), Ki67 and topoisomerase2-alpha (TOP2A) protein were routinely determined by means of immunohistochemistry [20]. A cut-off value of $\geq 10 \%$ was used for ER or PR positivity, and $>15 \%$ for TOP2A or Ki67 positivity. The HER2 status was determined via immunohistochemistry and/or HER2 FISH [20]. Immunohistochemistry data were not available for all patients.

Retrospective data collection. Additionally, we retrospectively extracted the following data from the pathological reports: the presence of multifocality, the sizes of the multiple foci (both invasive and in situ foci, if present), and the grade of the in situ component, if present. Pathological reports were considered only if there was a clear allusion to the presence or absence of more than one tumor focus. In all cases, largeformat histological sections (maximum size 60x90 mm) were examined according to Tot (21). The criterion of multifocality was the presence of more than one cancer focus separated by non-malignant breast tissue. If two or more invasive foci were present, the tumor was classified as invasive multifocal. Since most of the pathological reports did not provide the extent of the breast parenchyma involved by malignant structures, the pathological extent of the disease was estimated by summing the largest diameters of the invasive and in situ cancer foci; this measure was taken as the tumor burden. In unifocal cases, the tumor size comprised the tumor burden. Analyses were made on the basis of the presence of multifocality, the magnitude of the tumor burden, other pathological features and the survival data.
Survival data. Survival data were collected on the basis of regular 6-month follow-up visits or events such as relapse or death. Relapse-free survival (RFS) was defined as the time from breast surgery to any instance of disease recurrence (local, regional or distant relapse or a contralateral breast cancer). Breast cancer-specific survival (BCSS) was defined as the time from breast surgery to death of breast cancer. For the survival analyses, we excluded patients operated on after 2007. RFS and BCSS were studied in relation to the patient and tumor characteristics; the median value $(19 \mathrm{~mm})$ of the tumor burden was applied as a cut-off value. In order to detect a difference in outcome between the apparently early (cancers $<15 \mathrm{~mm}$ ) and more advanced cases as a function of the studied variables, survival analysis was performed separately on a subgroup of patients with breast cancers measuring $<15 \mathrm{~mm}$, regardless of whether they were unifocal or multifocal.

Statistical analyses. For the categorical parameters, the chi-square test was applied; for the analysis of continuous data, variance analysis and the Kruskal-Wallis test were used. The effects of the different patient and pathological characteristics on the disease outcome were assessed with the Kaplan-Meier method, and the effects of the various tumor-related factors on the disease outcome were evaluated with the Cox proportional hazards model. Statistical analysis was performed with SPSS 15.0 for Windows.

\section{Results}

Among a total of 1234 breast carcinoma cases, 1071 were eligible for the analysis. The mean $( \pm \mathrm{SD})$ age was $58.6 \pm 12.0$ (range 24.5-88.6) years. The patient and tumor characteristics are presented in Tables 1 and 2 . Around $40 \%$ of the cases were screen-detected.

Multifocality. Among the 796 (74.3\%) unifocal and 275 (25.7\%) multifocal cancers found, there were 101 multifocal invasive tumors, while in 174 cases a single invasive focus was associated with one or more in situ foci. Multifocal cancers were more susceptible to screen detection, HER2 positivity and casting calcifications in the mammogram than were unifocal cancers. Invasive multifocality was more strongly associated than non-invasive multifocality with mastectomy (44\% vs. $28 \%, \mathrm{p}<0.01$ ), lymph node positivity ( $47 \mathrm{vs.} 35 \%, \mathrm{p}=0.03$ ) and HER2 positivity ( 17 vs. $9 \%, \mathrm{p}=0.02$ ). The maximum diameter of unifocal cancers was than the largest tumor focus in multifocal cancers $(\mathrm{p}<0.001)$.

Tumor burden. The calculated mean $( \pm \mathrm{SE})$ tumor burden in the unifocal and the multifocal cases was $19.5 \pm 0.4$ and $31.2 \pm 0.9$, respectively $(p<0.001)$. We analysed the standard pathological parameters according to the tumor burden, using the median value of $19.0 \mathrm{~mm}$ as a threshold (Table 3 ). The presence of lymph node metastases $(p<0.001)$ or LVI $(p<0.001)$ was associated with a larger tumor burden. The mean $( \pm \mathrm{SE})$ tumor burden was $21.7 \pm 0.4$ vs. $28.9 \pm 1.4 \mathrm{~mm}$ in invasive ductal vs. lobular carcinomas, respectively $(\mathrm{p}<0.01)$. A larger invasive tumor focus and a larger tumor burden predisposed to ER, PR nega- 
Table 1. Patient-, tumor- and surgery-related parameters in unifocal and multifocal cancers

\begin{tabular}{|c|c|c|c|c|c|}
\hline Variable & & $\begin{array}{l}\text { Unifocal cancers } \\
\quad(n=796)(\%)\end{array}$ & $\begin{array}{l}\text { Multifocal cancers } \\
(\mathbf{n}=275) \\
(\%)\end{array}$ & $\mathbf{p}$ & $\begin{array}{c}\text { All } \\
(\mathrm{n}=1071) \\
(\%)\end{array}$ \\
\hline Age $($ mean \pm SD) & & $58.7 \pm 12.2$ & $58.5 \pm 11.5$ & 0.87 & $58.6 \pm 12.0$ \\
\hline \multirow[t]{2}{*}{ Mode of detection } & Screen-detected & $312(39.2)$ & $130(47.3)$ & 0.02 & $442(41.3)$ \\
\hline & Symptomatic+interval & $484(60.8)$ & $145(52.7)$ & & $629(58.7)$ \\
\hline \multirow[t]{3}{*}{ Mammographic appearance } & Stellate & $308(39.1)$ & $78(28.4)$ & $<0.001$ & $386(36.3)$ \\
\hline & Casting-type calcification \pm tumor mass & $35(4.4)$ & $51(18.5)$ & & $86(8.1)$ \\
\hline & Other & $444(56.4)$ & $146(53.1)$ & & $590(55.6)$ \\
\hline \multirow{2}{*}{ Breast surgery } & Excision & $570(71.6)$ & $186(67.6)$ & 0.22 & $756(70.6)$ \\
\hline & Mastectomy & $226(28.4)$ & $89(32.4)$ & & $315(29.4)$ \\
\hline \multirow[t]{2}{*}{ Lymph node surgery } & SNB or nothing & $382(48.0)$ & $139(50.5)$ & 0.48 & $382(48.6)$ \\
\hline & $\mathrm{ABD} \pm \mathrm{SNB}$ & $414(52.0)$ & $136(49.5)$ & & $414(51.4)$ \\
\hline
\end{tabular}

Table 2. Routinely assessed pathological parameters among unifocal, multifocal and invasive multifocal cancers

\begin{tabular}{|c|c|c|c|c|c|c|c|c|}
\hline Variable & & $\begin{array}{c}\text { Unifocal } \\
\text { cancers } \\
(\mathrm{n}=796) \\
(\%)\end{array}$ & $\begin{array}{c}\text { Multifocal } \\
\text { cancers } \\
(n=275)(\%)\end{array}$ & $\begin{array}{l}\text { p (multifocal } \\
\text { versus unifo- } \\
\text { cal) }\end{array}$ & $\begin{array}{c}\text { All } \\
(\mathbf{n}=1071) \\
(\%)\end{array}$ & $\begin{array}{c}\text { Invasive } \\
\text { multifocal } \\
\text { cancers } \\
(\mathbf{n}=101) \\
(\%)\end{array}$ & $\begin{array}{c}p \\
\text { (invasive } \\
\text { multifocal } \\
\text { versus } \\
\text { unifocal) }\end{array}$ & $\begin{array}{c}\text { All } \\
(\mathbf{n}=897) \\
(\%)\end{array}$ \\
\hline \multicolumn{2}{|l|}{ Tumor size $($ mean \pm SD) } & $19.5 \pm 10.8$ & $16.3 \pm 9.6$ & $<0.001$ & $18.6 \pm 10.6$ & $18.1 \pm 10.1$ & 0.24 & $19.3 \pm 10.7$ \\
\hline \multirow[t]{2}{*}{ Lymph node status } & $\mathbf{N}-$ & $510(64.1)$ & $173(62.9)$ & 0.77 & $683(63.8)$ & $54(53.5)$ & $<0.05$ & $564(62.9)$ \\
\hline & $\mathrm{N}+$ & $286(35.9)$ & $102(37.1)$ & & $388(36.2)$ & $47(46.5)$ & & $333(37.1)$ \\
\hline \multirow{3}{*}{$\begin{array}{l}\text { Histological type of the } \\
\text { invasive component }\end{array}$} & Invasive ductal carcinoma & $620(77.9)$ & $220(80.0)$ & 0.61 & $840(78.4)$ & $77(76.2)$ & 0.10 & $697(77.7)$ \\
\hline & Invasive lobular cancer & $93(11.7)$ & $32(11.6)$ & & $125(11.7)$ & $18(17.8)$ & & $111(12.4)$ \\
\hline & Other & $83(10.4)$ & $23(8.4)$ & & $106(9.9)$ & $6(5.9)$ & & $89(9.9)$ \\
\hline \multirow[t]{3}{*}{ Grade } & & & & & $\mathrm{n}=1062$ & & & $\mathrm{n}=888$ \\
\hline & Grade 1 & $113(14.3)$ & $45(16.5)$ & 0.38 & $158(14.9)$ & $16(16.2)$ & 0.65 & $129(14.5)$ \\
\hline & Grade 2 or 3 & $676(85.7)$ & $228(83.5)$ & & $904(85.1)$ & $83(83.8)$ & & $759(85.5)$ \\
\hline \multirow[t]{4}{*}{ Presence of DCIS } & & $\mathrm{n}=295$ & $\mathrm{n}=197$ & & $\mathrm{n}=492$ & $\mathrm{n}=58$ & & $\mathrm{n}=353$ \\
\hline & Grade 1 & $40(13.6)$ & $24(12.2)$ & 0.49 & $4(13.0)$ & $9(15.5)$ & 0.06 & $49(13.9)$ \\
\hline & Grade 2 & $85(28.8)$ & $49(24.9)$ & & $134(27.2)$ & $25(43.1)$ & & $110(31.2)$ \\
\hline & Grade 3 & $170(57.6)$ & $124(62.9)$ & & $294(59.8)$ & $24(41.4)$ & & $194(55.0)$ \\
\hline \multirow[t]{2}{*}{ Presence of LVI } & LVI- & $648(81.4)$ & $224(81.5)$ & 1.00 & $872(81.4)$ & $88(87.1)$ & 0.17 & $736(82.1)$ \\
\hline & LVI+ & $148(18.6)$ & $51(18.5)$ & & $199(18.6)$ & $13(12.9)$ & & $161(17.9)$ \\
\hline \multirow[t]{3}{*}{ ER status } & & & & & $\mathrm{n}=1067$ & & & $\mathrm{n}=893$ \\
\hline & ER+ & $606(76.5)$ & $198(72.0)$ & 0.14 & $804(75.4)$ & $78(77.2)$ & 1.00 & $684(76.6)$ \\
\hline & ER- & $186(23.5)$ & $77(28.0)$ & & $263(24.6)$ & $23(22.8)$ & & $209(23.4)$ \\
\hline \multirow[t]{3}{*}{ PR status } & & & & & $\mathrm{n}=1069$ & & & $\mathrm{n}=895$ \\
\hline & PR+ & $565(70.9)$ & $180(65.5)$ & 0.09 & $743(69.5)$ & $70(69.3)$ & 0.73 & $633(70.7)$ \\
\hline & PR- & $231(29.1)$ & $95(34.5)$ & & $326(30.5)$ & $31(30.7)$ & & $262(29.3)$ \\
\hline \multirow[t]{3}{*}{ Ki67 status } & & & & & $\mathrm{n}=362$ & & & $\mathrm{n}=321$ \\
\hline & Ki67+ & $119(40.8)$ & $37(52.9)$ & 0.08 & $156(43.1)$ & $15(51.7)$ & 0.32 & $134(41.7)$ \\
\hline & Ki67- & $173(59.2)$ & $33(47.1)$ & & $206(56.9)$ & $14(48.3)$ & & $187(58.3)$ \\
\hline \multirow[t]{3}{*}{ TOP2A status } & & & & & $\mathrm{n}=283$ & & & $\mathrm{n}=247$ \\
\hline & TOP2A+ & $59(26.6)$ & $19(31.1)$ & 0.52 & $78(27.6)$ & $8(32.0)$ & 0.64 & $67(27.1)$ \\
\hline & TOP2A- & $163(73.4)$ & $42(68.9)$ & & $205(72.4)$ & $17(68.0)$ & & $180(72.9)$ \\
\hline \multirow[t]{3}{*}{ HER2 status } & & & & & $\mathrm{n}=1048$ & & & $\mathrm{n}=879$ \\
\hline & HER2+ & $58(7.4)$ & $46(17.2)$ & $<0.001$ & $104(9.9)$ & $17(17.3)$ & 0.003 & $75(8.5)$ \\
\hline & HER2- & $723(92.6)$ & $221(82.8)$ & & $944(90.1)$ & $81(82.7)$ & & $804(91.5)$ \\
\hline \multirow[t]{3}{*}{ Triple negativity } & & & & & $\mathrm{n}=1063$ & & & $\mathrm{n}=890$ \\
\hline & Yes & $106(13.4)$ & $26(9.5)$ & 0.09 & $132(12.4)$ & $7(6.9)$ & 0.08 & $113(12.7)$ \\
\hline & No & $683(86.6)$ & $248(90.5)$ & & $931(87.6)$ & $94(93.1)$ & & $777(87.3)$ \\
\hline
\end{tabular}


Table 3. Routinely assessed pathological parameters in 1071 breast cancers according to tumor burden

\begin{tabular}{|c|c|c|c|c|}
\hline Variable & & $\begin{array}{l}\text { Tumor burden } \leq 19 \mathrm{~mm} \\
\qquad(\mathrm{n}=536)\end{array}$ & $\begin{array}{c}\text { Tumor burden }>19 \mathrm{~mm} \\
\qquad(\mathrm{n}=535)\end{array}$ & $\mathbf{p}$ \\
\hline Tumor size (mean \pm SD) & & $12.4 \pm 3.9$ & $24.9 \pm 11.4$ & $<0.001$ \\
\hline \multirow[t]{2}{*}{ Lymph node status } & $\mathrm{N}-$ & $383(71.5)$ & $300(56.1)$ & $<0.001$ \\
\hline & $\mathrm{N}+$ & $153(28.5)$ & $235(43.9)$ & \\
\hline \multirow[t]{3}{*}{ Histological type } & Invasive ductal carcinoma & $437(81.5)$ & $403(75.3)$ & 0.01 \\
\hline & Invasive lobular cancer & $46(8.6)$ & $79(14.8)$ & \\
\hline & Other & $53(9.9)$ & $53(9.9)$ & \\
\hline \multirow[t]{2}{*}{ Grade } & Grade 1 & $118(22.2)$ & $40(7.5)$ & $<0.001$ \\
\hline & Grade 2 or 3 & $411(77.8)$ & $490(92.5)$ & \\
\hline \multirow[t]{4}{*}{ Presence of DCIS } & & $\mathrm{n}=219(44.5 \%$ of all $)$ & $\mathrm{n}=273(55.5 \%$ of all $)$ & $<0.001$ \\
\hline & Grade 1 & $44(20.1)$ & $20(7.3)$ & \\
\hline & Grade 2 & $69(31.5)$ & $65(23.8)$ & \\
\hline & Grade 3 & $106(48.4)$ & $188(68.9)$ & \\
\hline \multirow[t]{2}{*}{ Presence of LVI } & LVI- & $460(85.8)$ & $412(77.0)$ & $<0.001$ \\
\hline & LVI+ & $76(14.2)$ & $123(23.0)$ & \\
\hline ER status & ER+ & $436(82.0)$ & $368(68.8)$ & $<0.001$ \\
\hline $\mathrm{n}=1067$ & ER- & $96(18.0)$ & $167(31.2)$ & \\
\hline PR status & PR+ & $403(75.5)$ & $340(63.6)$ & $<0.001$ \\
\hline$n=1069$ & PR- & $131(24.5)$ & $195(36.4)$ & \\
\hline Ki67 status & Ki67+ & $76(37.4)$ & $80(50.3)$ & 0.02 \\
\hline$n=362$ & Ki67- & $127(62.6)$ & $79(49.7)$ & \\
\hline TOP2A status & TOP2A+ & $38(24.7)$ & $40(31.0)$ & 0.29 \\
\hline $\mathrm{n}=283$ & TOP2A- & $116(75.3)$ & $89(69.0)$ & \\
\hline \multirow[t]{2}{*}{ HER2 status $n=1048$} & HER2+ & $39(7.4)$ & $65(12.4)$ & 0.01 \\
\hline & HER2- & $486(92.6)$ & $458(87.6)$ & \\
\hline Multifocality & Yes & $60(11.2)$ & $215(40.2)$ & $<0.001$ \\
\hline$n=1071$ & No & $476(88.8)$ & $320(59.8)$ & \\
\hline
\end{tabular}

tivity $(\mathrm{p}<0.001)$ and HER2 positivity $(\mathrm{p}<0.001)$. In multivariate analysis, only the connections between the tumor burden and ER, PR negativity and HER2 positivity remained significant $(\mathrm{p}<0.001)$. A larger tumor burden was associated with Ki67 positivity $(\mathrm{p}=0.02)$. A tumor burden larger than the cut-off value was related to multifocality $(\mathrm{p}<0.001)$. The mean $( \pm \mathrm{SE})$ tumor burden was $32.6 \pm 0.2 \mathrm{~mm}$ in cases where there were casting calcifications in the mammogram, and $20.9 \pm 0.6 \mathrm{~mm}$ when the lesion was categorized as a spiculated mass $(\mathrm{p}<0.001)$.

Survival. The median follow-up time for the population of 584 patients participating in the survival analysis was 5.0 (range 0.3-7.3) years, while that in the subgroup of 233 patients with cancers measuring $<15 \mathrm{~mm}$, was $5.2(0.5-7.3)$ years. In the overall population, there were 65 relapses $(12.7 \%)$ and 30 deaths (5.8\%), while among the patients with cancers measuring $<15 \mathrm{~mm}$ in size, there were 11 relapses $(5.5 \%)$ and 2 deaths $(1.0 \%)$. In the overall population, the numbers of relapses and deaths in the multifocal vs. the unifocal cases, respectively were 17 vs. 48 and 7 vs. 23 . The survival data did not differ as a function of the presence of multifocality in the entire population or in the subgroup with cancers $<15 \mathrm{~mm}$ in size (Table 4). In the latter group, the OS analysis was omitted because of the low number of events.

Among the conventional tumor characteristics including the histological type, the expression of hormone receptors and the Ki67 and HER2 status, only a larger invasive tumor, the presence of LVI or lymph node involvement, HER2 positivity and triple negativity were associated with a poorer RFS and OS (Table 4). The grade of the invasive tumor was not related to the RFS. As regards the mode of detection, screendetected tumors gave RFS and OS statistics that were superior to those for non-screen-detected or interval cancers. The mammographic appearance of the tumor was not related to the outcome. A tumor burden $>19 \mathrm{~mm}$ or $>40 \mathrm{~mm}$ (extensive tumor) involved a shorter RFS and OS. Neither multifocality nor invasive multifocality was associated with a shorter RFS or OS. Among tumors $<15 \mathrm{~mm}$ in size, only HER 2 positivity was related to a poorer RFS.

In Cox proportional hazards models, the largest invasive tumor size, the lymph node status, triple negativity and HER2 positivity remained independent determinants of an increased risk of relapse or death (Tables 5 and 6).

\section{Discussion}

Our analysis indicated that, although multifocal breast tumors (frequently screen-detected) are often smaller than unifocal breast tumors, the aggregate size and hence the load of the cancer are larger, as an indication of a higher risk of dissemination. The relatively high proportion of lymph 
Table 4. The effects of selected variables on disease outcome (median RFS and OS) among the cases participating in the survival analysis, and in the subgroup of patients with tumors $<15 \mathrm{~mm}$

\begin{tabular}{|c|c|c|c|}
\hline & \multicolumn{2}{|c|}{ Overall population $(n=584)$} & \multirow{2}{*}{$\begin{array}{c}\mathbf{p T}<\mathbf{1 5} \mathbf{~ m m}(\mathbf{n}=\mathbf{2 3 3}) \\
\text { RFS } \\
\text { estimated mean }( \pm \text { SE, years })\end{array}$} \\
\hline & $\begin{array}{c}\text { RFS } \\
\text { estimated mean }( \pm \text { SE, years })\end{array}$ & $\begin{array}{c}\text { OS } \\
\text { estimated mean }( \pm \text { SE, years })\end{array}$ & \\
\hline \multicolumn{4}{|l|}{ Largest invasive tumor } \\
\hline$<15 \mathrm{~mm}$ & $7.0 \pm 0.1$ & $7.3 \pm 0.0$ & - \\
\hline$\geq 15 \mathrm{~mm}$ & $6.4 \pm 0.1$ & $6.9 \pm 0.1$ & - \\
\hline$p$ (Mantel-Cox) & $<0.001$ & $<0.001$ & - \\
\hline \multicolumn{4}{|l|}{ Lymph node positivity } \\
\hline Yes & $6.1 \pm 0.2$ & $6.8 \pm 0.1$ & $6.6 \pm 0.3$ \\
\hline No & $7.0 \pm 0.1$ & $7.2 \pm 0.0$ & $7.2 \pm 0.1$ \\
\hline$p$ (Mantel-Cox) & $<0.001$ & $<0.001$ & $=0.08$ \\
\hline \multicolumn{4}{|l|}{ Invasive tumor grade } \\
\hline 1 & $6.9 \pm 0.2$ & $7.3^{*}$ & $7.0 \pm 0.2$ \\
\hline 2 or 3 & $6.6 \pm 0.1$ & $6.9 \pm 0.6$ & $6.9 \pm 0.1$ \\
\hline$p$ (Mantel-Cox) & $=0.17$ & $=0.03$ & $=0.80$ \\
\hline \multicolumn{4}{|l|}{ Presence of LVI } \\
\hline Yes & $6.2 \pm 0.2$ & $6.7 \pm 0.1$ & $6.2 \pm 0.3$ \\
\hline No & $6.8 \pm 0.1$ & $7.2 \pm 0.1$ & $7.1 \pm 0.1$ \\
\hline$p$ (Mantel-Cox) & $=0.02$ & $=0.004$ & $=0.31$ \\
\hline \multicolumn{4}{|l|}{ HER2 } \\
\hline Positive & $5.7 \pm 0.4$ & $6.3 \pm 0.2$ & $5.8 \pm 0.6$ \\
\hline Negative & $6.7 \pm 0.1$ & $7.1 \pm 0.1$ & $7.1 \pm 0.1$ \\
\hline$p$ (Mantel-Cox) & $<0.001$ & $<0.001$ & $<0.001$ \\
\hline \multicolumn{4}{|l|}{ Triple negative } \\
\hline Yes & $6.0 \pm 0.3$ & $6.5 \pm 0.2$ & $6.4 \pm 0.3$ \\
\hline No & $6.7 \pm 0.1$ & $7.1 \pm 0.1$ & $7.1 \pm 0.1$ \\
\hline$p$ (Mantel-Cox) & $=0.02$ & $=0.002$ & $=0.31$ \\
\hline \multicolumn{4}{|l|}{ Mode of detection } \\
\hline Screen-detected & $6.9 \pm 0.1$ & $7.2 \pm 0.1$ & $7.1 \pm 0.1$ \\
\hline Interval and non-screen-detected cancer & $6.4 \pm 0.1$ & $6.9 \pm 0.1$ & $6.9 \pm 0.2$ \\
\hline$p$ (Mantel-Cox) & $=0.001$ & $=0.01$ & $=0.69$ \\
\hline \multicolumn{4}{|l|}{ Mammographic appearance } \\
\hline Spiculated tumor mass without casting calcification & $6.7 \pm 0.1$ & $7.1 \pm 0.1$ & $7.2 \pm 0.1$ \\
\hline Casting calcification \pm tumor mass & $6.4 \pm 0.3$ & $6.9 \pm 0.2$ & $6.0 \pm 0.4$ \\
\hline Other & $6.7 \pm 0.1$ & $7.1 \pm 0.1$ & $6.9 \pm 0.1$ \\
\hline$p$ (Mantel-Cox) & $=0.66$ & $=0.70$ & $=0.49$ \\
\hline \multicolumn{4}{|l|}{ Multifocality } \\
\hline Yes & $6.6 \pm 0.1$ & $7.0 \pm 0.1$ & $6.9 \pm 0.1$ \\
\hline No & $6.7 \pm 0.1$ & $7.1 \pm 0.1$ & $7.0 \pm 0.1$ \\
\hline$p$ (Mantel-Cox) & $=0.45$ & $=0.59$ & $=0.93$ \\
\hline \multicolumn{4}{|l|}{ Invasive multifocality } \\
\hline Yes & $6.5 \pm 0.3$ & $7.1 \pm 0.1$ & $6.2 \pm 0.4$ \\
\hline No & $6.7 \pm 0.1$ & $6.9 \pm 0.1$ & $7.1 \pm 0.1$ \\
\hline$p$ (Mantel-Cox) & $=0.94$ & $=0.70$ & $=0.12$ \\
\hline \multicolumn{4}{|l|}{ Tumor burden } \\
\hline$\leq 19 \mathrm{~mm}$ & $6.7 \pm 0.1$ & $7.1 \pm 0.1$ & $6.8 \pm 1.1$ \\
\hline$>19 \mathrm{~mm}$ & $6.5 \pm 0.1$ & $6.9 \pm 0.1$ & $7.3^{*}$ \\
\hline$p$ (Mantel-Cox) & $=0.09$ & $=0.03$ & $=0.09$ \\
\hline \multicolumn{4}{|l|}{ Tumor burden } \\
\hline$<40 \mathrm{~mm}$ & $6.7 \pm 0.1$ & $7.1 \pm 0.1$ & $7.0 \pm 0.1$ \\
\hline$\geq 40 \mathrm{~mm}$ & $5.9 \pm 0.3$ & $6.5 \pm 0.2$ & $7.0^{*}$ \\
\hline$p$ (Mantel-Cox) & $=0.04$ & $=0.02$ & $=0.42$ \\
\hline
\end{tabular}

${ }^{\star}$ All cases are censored 
Table 5. The effects of selected patient- and tumor-related features on the risk of relapse according to the Cox proportional hazards model: univariate and multivariate analysis

\begin{tabular}{|c|c|c|c|c|}
\hline Variable & $\begin{array}{c}\text { Univariate } \\
\text { HR (95\% CI) }\end{array}$ & $\mathbf{p}$ & Multivariate HR (95\% CI) & $\mathbf{p}$ \\
\hline pT $\geq 15$ vs. $<15 \mathrm{~mm}$ & $3.4(1.8-6.5)$ & $<0.001$ & $2.0(1.0-4.0)$ & 0.05 \\
\hline Lymph node-positive vs. lymphnode-negative & $3.8(2.3-6.4)$ & $<0.001$ & $3.0(1.7-5.3)$ & $<0.001$ \\
\hline Grade $2-3$ vs. grade 1 (invasive component) & $1.9(0.8-4.7)$ & 0.17 & & \\
\hline Presence of LVI & $1.8(1.1-2.9)$ & 0.02 & $1.1(0.6-1.7)$ & 0.97 \\
\hline HER2 positivity & $2.9(1.7-5.3)$ & $<0.001$ & $3.1(1.7-5.8)$ & $<0.001$ \\
\hline Triple negativity & $1.8(0.9-3.4)$ & 0.06 & $2.2(1.1-4.4)$ & 0.02 \\
\hline Non-screen-detected or interval vs. screen-detected & $2.5(1.4-4.3)$ & $<0.001$ & $1.6(0.9-2.8)$ & 0.15 \\
\hline Casting calcification vs. spiculated tumor mass & $1.5(0.6-3.8)$ & 0.37 & & \\
\hline Spiculated tumor mass vs. other & $1.1(0.7-1.9)$ & 0.69 & & \\
\hline Presence of multifocality & $0.8(0.5-1.4)$ & 0.45 & & \\
\hline Tumor burden $>19 \mathrm{~mm}$ & $1.5(0.9-2.6)$ & 0.09 & & \\
\hline Tumor burden $>40 \mathrm{~mm}$ & $1.8(1.1-3.4)$ & 0.05 & $1.0(0.5-2.0)$ & 0.98 \\
\hline
\end{tabular}

Table 6. The effects of selected patient- and tumor-related features on the risk of death due to breast cancer according to the Cox proportional hazards model: univariate and multivariate analysis

\begin{tabular}{|c|c|c|c|c|}
\hline Category & $\begin{array}{c}\text { Univariate } \\
\text { HR (95\% CI) }\end{array}$ & $\mathbf{p}$ & Multivariate HR (95\% CI) & $\mathbf{p}$ \\
\hline $\mathrm{pT} \geq 15$ vs. $<15 \mathrm{~mm}$ & $8.9(2.1-37.7)$ & 0.03 & $2.5(1.2-5.2)$ & 0.03 \\
\hline Lymph node positivity & $5.0(2.1-11.9)$ & $<0.001$ & $3.3(1.4-8.2)$ & 0.01 \\
\hline Grade $2-3$ vs. grade 1 (invasive component) & $25.2(0.2-3012.88)$ & 0.18 & & \\
\hline Presence of LVI & $2.9(1.3-6.1)$ & 0.01 & $1.3(0.6-3.0)$ & 0.48 \\
\hline HER2 positivity & $5.8(2.6-12.7)$ & $<0.001$ & $8.4(3.2-22.1)$ & $<0.001$ \\
\hline Triple negativity & $3.5(1.5-8.1)$ & 0.003 & $6.8(2.5-18.5)$ & $<0.001$ \\
\hline Non-screen-detected or interval vs. screen-detected & $3.7(1.4-9.6)$ & 0.01 & $2.3(0.8-6.9)$ & 0.13 \\
\hline Casting calcification vs. spiculated tumor mass & $1.7(0.5-6.4)$ & 0.42 & & \\
\hline Spiculated tumor mass vs. other & $1.3(0.5-3.0)$ & 0.59 & & \\
\hline Presence of multifocality & $0.8(0.3-1.9)$ & 0.59 & & \\
\hline Tumor burden $>19 \mathrm{~mm}$ & $2.6(1.1 .-6.1)$ & 0.03 & $0.8(0.3-2.1)$ & 0.65 \\
\hline Tumor burden $>40 \mathrm{~mm}$ & $2.6(1.1-6.2)$ & 0.03 & $0.9(0.3-2.7)$ & 0.94 \\
\hline
\end{tabular}

node-positive cases in invasive multifocal cancers reflects their aggressive behaviour and advanced stage. Although our results do not support the role of multifocality as an independent predictor of a worse prognosis, they should warn against the consideration of only a single tumor focus rather than the whole extent of the disease if multiple cancer foci are present so as to avoid false judgement. It is important that multifocal breast cancers are a special type with a poorer prognosis; they are often HER2- positive and associated with casting-type microcalcifications in the mammogram. Lobular histology favoured larger tumor burden.

In our study, multifocality and "invasive multifocality" occurred within the ranges reported by other authors [16, $18,22]$. There are a number of reasons how to explain the discrepancies between the findings. Some authors do not distinguish between multicentric (situated in different quadrants of the breast) and multifocal cancers [12], and include tumors with a single invasive focus and in situ components [18], whereas others regard tumors as multifocal only if more than one invasive focus is present $[1,11,13-16,18]$. The strength of our study is that we relied on data recorded in thorough examinations of large-format histopathology slides. Nonetheless the retrospective nature of the study is a disadvantage.

The UICC/AJC TNM system is used as a prognostic tool, and the TNM stage has long served as the basis of therapy decision-making. A major flaw is that, in cases of multifocality, the $\mathrm{T}$ stage indicates the largest invasive focus of the disease, but ignores the effective tumor burden, which may be significant if multiple foci are present. Our study accords with the findings of others in that the TNM system in its current form is not suitable for these purposes in the population of multifocal breast cancers $[9,11,12,15,23,24]$. We found that, despite the tumor being smaller, lymph node positivity was 
more prevalent among cancers containing multiple invasive foci, and a larger aggregate tumor burden involved a poorer outcome. These results are in accordance with those $[9,10,12$, $14,16,18]$ indicating that multifocality is related to lymph node positivity. Moreover, Tot et al. found multifocal and diffuse lesion distribution to be an independent predictor of breast cancer-related fatality [18]. In fact, the diffuse distribution of the lesions is a rarely described phenomenon, and consequently its effect should rather be analysed prospectively [23]. We could not recover this type of tumor from the pathology records; such cases were probably classified as unifocal, which could play a role in the incongruence between the findings of Tot et al. and ourselves [18]. Nevertheless, our results conform to the view that a consideration of multifocality is demanded in every breast cancer specimen.

For the estimation of tumor extent, we calculated the tumor burden by summing the largest diameters of the tumor foci. This method provides merely an approximation; only exact measurement of the entire tumor extent, encompassing the whole of the affected part of the breast parenchyma, would furnish accurate information. For the estimation of tumor burden, different approaches have been utilized in the literature. For assessment of the tumor burden of multifocal cancers and the effect on survival, Rezo et al. used aggregate sizes and volumes of the tumor foci, calculated as though they were spherical [16]. Interestingly, all measures gave similar results: increasing tumor size predicted a poorer outcome after 60 months of follow-up. Others followed the same method as we did, using the combined diameters of the tumor foci $[9,11,14]$.

The effect of multifocality on prognosis is controversial. Similarly to our findings, Cabioglu et al. concluded that the presence of multiple invasive foci favoured lymph node positivity, and the 55 month-survival did not differ between multifocal and unifocal cases [14]. Yerushalmi et al. analysed a dataset on more than 25,000 cases, and found that multifocality carried a $17 \%$ extra risk of breast cancer-related death in stage I-III breast cancers [15]. In a matched-pair analysis of 288 breast cancer cases, Weissenbacher et al likewise showed that both the risk of relapse and that of death due to breast cancer were increased in multifocal cancers [12]. Boyages et al. demonstrated a better 10 -year survival rate among unifocal breast cancer cases than among multifocal breast cancer cases, but this effect was restricted to tumors $>20 \mathrm{~mm}$ [11]. In a series of 574 breast cancer cases, Tot et al. observed a significantly poorer breast cancer-specific survival rate in multifocal cancers, irrespective of whether only invasive or invasive plus in situ multifocal cases were included [18]. We did not detect a difference in survival between the cases with multifocal and unifocal breast cancers, but tumor size, lymph node status and HER2-positive or triple negative status were independent predictors of outcome. The relatively low overall number of events and short follow-up times could have played a role in these results.

\section{Conclusions}

For the adequate management of breast cancer, an appropriate assessment of the tumor distribution is essential; heightened attention is needed during the care of multifocal breast cancers, which present in a more advanced stage than estimated from the consideration of only the largest focus.

Acknowledgements: The authors are grateful to Dr. Tibor Tot for his advice regarding the study.

\section{References}

[1] TOT T The metastatic capacity of multifocal breast carcinomas: extensive tumors versus tumors of limited extent. Hum Pathol 2009; 40: 199-205. http://dx.doi.org/10.1016/ j.humpath.2008.07.001

[2] TABAR L, CHEN THH, YEN AMF, TOT T, TUNG TH et al. Mammographic tumor features can predict long-term outcomes reliably in women with 1-14-mm invasive breast carcinoma. Cancer 2004; 101: 1745-1759. http://dx.doi. org/10.1002/cncr.20582

[3] TOT T, KAHAN Z A new approach to early breast cancer. In: Breast cancer, a heterogeneous disease entity. The very early stages. Springer, Dordrecht, Heidelberg, London, New York, 2011. pp. 1-22. http://dx.doi.org/10.1007/978-94-007-0489-3 1

[4] KAHAN Z New approaches for the classification of early breast cancer, a heterogeneous disease entity. memo, 2011; 4: 135-139.

[5] MAJEK O, DANES J, SKOVAJSOVA M, BARTONKOVA H, BURESOVA L et al. Breast cancer screening in the Czech Republic: time trends in performance indicators during the first seven years of the organised programme. BMC Public Health 2011; 11: 288. http://dx.doi.org/10.1186/1471-2458-11-288

[6] GILL PG, FARSHID G, LUKE CG, RODER DM Detection by screening mammography is a powerful independent predictor of survival in women diagnosed with breast cancer. Breast 2004; 13: 15-22. http://dx.doi.org/10.1016/S09609776(03)00169-3

[7] JOENSUU H, LEHTIMAKI T, HOLLI K, ELOMAA L, TURPEENNIEMI-HUJANEN T et al. Risk for distant recurrence of breast cancer detected by mammography screening or other methods. JAMA 2004; 292: 1064-1073. http://dx.doi. org/10.1001/jama.292.9.1064

[8] TABAR L, CHEN HH, DUFFY SW, YEN MF, CHIANG CF et al. A novel method for prediction of long-term outcome of women with T1a, T1b, and 10-14 mm invasive breast cancers: a prospective study. Lancet 2000; 355: 429-433.

[9] ANDEA AA, BOUWMAN D, WALLIS T, VISSCHER DW Correlation of tumor volume and surface area with lymph node status in patients with multifocal/multicentric breast carcinoma. Cancer 2004; 100: 20-27. http://dx.doi. org/10.1002/cncr.11880

[10] COOMBS NJ, BOYAGES J Multifocal and multicentric breast cancer: does each focus matter? J Clin Oncol 2005; 23 : 7497-7502. http://dx.doi.org/10.1200/JCO.2005.02.1147 
[11] BOYAGES J, JAYASINGHE UW, COOMBS N Multifocal breast cancer and survival: each focus does matter particularly for larger tumors. Eur J Cancer 2010; 46: 1990-1996. http:// dx.doi.org/10.1016/j.ejca.2010.03.003

[12] WEISSENBACHER TM, ZSCHAGE M, JANNI W, JESCHKE $\mathrm{U}$, DIMPFL $\mathrm{T}$ et al. Multicentric and multifocal versus unifocal breast cancer: is the tumor-node-metastasis classification justified? Breast Cancer Res Treat 2010; 122: 27-34. http://dx.doi.org/10.1007/s10549-010-0917-9

[13] TOT T, PEKAR G, HOFMEYERS, SOLLIE T, GERE M, TARJAN M The distribution of lesions in 1-14-mm invasive breast carcinomas and its relation to metastatic potential. Virchows Arch 2009; 455: 109-115. http://dx.doi.org/10.1007/s00428-009-0808-9

[14] CABIOGLU N, OZMEN V, KAYA H, TUZLALI S, IGCI A et al. Increased lymph node positivity in multifocal and multicentric breast cancer. J Am Coll Surg 2009; 208: 67-74. http://dx.doi.org/10.1016/j.jamcollsurg.2008.09.001

[15] YERUSHALMI R, KENNECKE H, WOODS R, OLIVOTTO IA, SPEERS C et al. Does multicentric/multifocal breast cancer differ from unifocal breast cancer? An analysis of survival and contralateral breast cancer incidence. Breast Cancer Res Treat 2009; 117: 365-370. http://dx.doi.org/10.1007/s10549-008$\underline{0265-1}$

[16] REZO A, DAHLSTROM J, SHADBOLT B, RODINS K, ZHANG $Y$ et al. Tumor size and survival in multicentric and multifocal breast cancer. Breast 2011; 20: 259-263. http:// dx.doi.org/10.1016/j.breast.2011.01.005

[17] KURTZ JM, JACQUEMIER J, AMALRIC R, BRANDONE H, AYME $Y$ et al. Breast-conserving therapy for macroscopically multiple cancers. Ann Surg 1990; 212: 38-44. http://dx.doi. org/10.1097/00000658-199007000-00006
[18] TOT T, GERE M, PEKAR G, TARJEB M, HOFMEYER S et al. Breast cancer multifocality, disease extent, and survival. Hum Pathol 2011; 42: 1761-9. http://dx.doi.org/10.1016/ j.humpath.2011.02.002

[19] PALKA I, KELEMEN G, ORMANDI K, LAZAR G, NYARI $\mathrm{T}$ et al. Tumor characteristics in screen-detected and symptomatic breast cancers. Pathol Oncol Res 2008; 14: 161-167. http://dx.doi.org/10.1007/s12253-008-9010-7

[20] NIKOLENYI A, SUKOSD F, KAIZER L, CSORGO E, VOROS A et al. Tumor topoisomerase II alpha status and response to anthracycline-based neoadjuvant chemotherapy in breast cancer. Oncology 2011; 80: 269-277. http://dx.doi. org/10.1159/000329038

[21] BENDIFALLAH S, WERKOFF G, BORIE-MOUTAFOFF C, ANTOINE M, CHOPIER J et al. Multiple synchronous (multifocal and multicentric) breast cancer: clinical implications. Surg Oncol 2010; 19: 115-23. http://dx.doi.org/10.1016/ j.suronc.2010.06.001

[22] TOT T Large-format histology, a prerequisite for adequate assesment of early breast carcinomas. In: Breast cancer, a heterogeneous disease entity. The very early stages. Springer, Dordrecht, Heidelberg, London, New York, 2011. pp. $57-88$.

[23] TOT T The diffuse type of invasive lobular carcinoma of the breast: morphology and prognosis. Virchows Arch 2003; 443: 718-724. http://dx.doi.org/10.1007/s00428-003-0881$\underline{4}$

[24] TOT T, PEKAR GY Multifocality in „basal-like” breast carcinomas and its influence on lymph node status. Ann Surg Oncol 2011; 18: 1671-1677. http://dx.doi.org/10.1245/s10434$\underline{010-1480-7}$ 